\title{
Improved Therapeutic Profiles of PLA 2 -Free Bee Venom Prepared by Ultrafiltration Method
}

\author{
Hyunkyoung Lee ${ }^{1,2, \dagger}$, Min-Jung Pyo ${ }^{1,2,+}$, Seong Kyeong Bae ${ }^{1}$, Yunwi Heo ${ }^{1}$, Choul Goo Kim ${ }^{3}$, \\ Changkeun Kang ${ }^{1,4}$ and Euikyung Kim ${ }^{1,2}$ \\ ${ }^{1}$ College of Veterinary Medicine, Gyeongsang National University, Jinju, Korea \\ ${ }^{2}$ Institute of Animal Medicine, Gyeongsang National University, Jinju, Korea \\ ${ }^{3}$ Chung Jin Biotech Co., Ltd., Hanyang University Business Center, Anshan-si, Korea \\ ${ }^{4}$ Institutes of Agriculture and Life Science, Gyeongsang National University, Jinju, Korea
}

(Received October 14, 2014; Revised November 18, 2014; Accepted November 26, 2014)

\begin{abstract}
Bee venom (BV) has long been used in traditional Eastern and Western medicine for chronic inflammation, pain and skin therapy. Human exposure to BV, however, often causes unwanted adverse effects and is even fatal in some cases. Phospholipase $\mathrm{A}_{2}\left(\mathrm{PLA}_{2}\right)$ of $\mathrm{BV}$ is now suspected to play a key role in these adverse effects. We investigated the potential use of $\mathrm{PLA}_{2}$-free bee venom (PBV) as a replacement for BV in cosmetic products. PBV prepared by molecular weight cut-off ultrafiltration exhibits a superior profile in comparison with regular BV, by inhibiting elastase activity and suppressing the induction of nitric oxide (NO) and metalloproteinase-9 (MMP-9), while retaining the effects of cell proliferation and protection against ultraviolet B (UVB)-induced damage in human dermal fibroblast cells. PBV thus appears to be more promising than $\mathrm{BV}$ as a cosmetic ingredient with a reduced potential for adverse reactions in the recipient.
\end{abstract}

Key words: Bee venom, Phospholipase $\mathrm{A}_{2}$ free, Ultrafiltration, Human dermal fibroblast, Ultraviolet B, Cosmetic product

\section{INTRODUCTION}

Bee venom (BV) is a complex mixture of proteins, peptides, and small molecular components, such as phospholipase $\mathrm{A}_{2}\left(\mathrm{PLA}_{2}\right)$, melittin, apamin, mast cell degranulating peptide, histamine, and dopamine (1). It has long been used for the treatments of chronic inflammation (rheumatoid arthritis), skin disease (acne and itch) and for pain relief in traditional medicine for thousands of years $(2,3)$. In fact, several studies have previously reported that BV has antiinflammatory and antinociceptive effects in various experimental animal models $(4,5)$. Other investigators have demonstrated that $\mathrm{BV}$ inhibited tumor growth and showed antitumor activity in both, in vitro and in vivo assays, that

Correspondence to: Euikyung Kim, College of Veterinary Medicine, Gyeongsang National University, Jinju 660-701, Korea

E-mail: ekim@gnu.ac.kr

These authors contributed equally to this work.

This is an Open-Access article distributed under the terms of the Creative Commons Attribution Non-Commercial License (http:// creativecommons.org/licenses/by-nc/3.0) which permits unrestricted non-commercial use, distribution, and reproduction in any medium, provided the original work is properly cited. are suggestive of an anticancer therapeutic against malignancy $(6,7)$. Recently, BV has also aroused interest as a cosmetic ingredient due to its protective, antibacterial and antiinflammatory effects on the skin (2). However, the occasional adverse effects (allergy reaction and severe anaphylactic shock) of $\mathrm{BV}$ have limited its utilization. $\mathrm{PLA}_{2}$ is considered the prime cause of allergic reactions in patients exposed to BV. It stimulates cross-linking of immunoglobin $\mathrm{E}(\mathrm{IgE})$ with mast cells and basophils, as well as leukotriene production through the hydrolysis of phospholipids (8).

BV is reportedly effective against inflammatory diseases, such as multiple sclerosis, asthma, or polyneuritis. Furthermore, there are reports of $\mathrm{BV}$ therapy for the treatment of various rheumatisms $(9,10)$ and inflammation (1). Inflammation is usually associated with various pro-inflammatory mediators, including $\mathrm{NO}$ and prostaglandin $\mathrm{E}_{2}\left(\mathrm{PGE}_{2}\right)$, which are the markers of inflammatory reactions. $\mathrm{PGE}_{2}$ has been shown to increase the levels of cytosolic phospholiase $\mathrm{A}_{2}\left(\mathrm{cPLA}_{2}\right)$ and cyclooxygenase (COX), resulting in the amplification of their own production and the synthesis of inflammatory cytokines (11). NO is rapidly induced when stimulated with inflammatory environments, such as lipo- 
polysaccharides (LPS) and pathogens. Large amounts of $\mathrm{NO}$ are generated by inducible NO synthase (iNOS) in activated macrophages (12). Subsequently, many effectors of NO production can lead to the simultaneous release of proinflammatory mediators, such as $\mathrm{PGE}_{2}$ and prostaglandin $\mathrm{I}_{2}$ $\left(\mathrm{PGI}_{2}\right)$ from the COX pathway. NO is an important indicator of inflammatory response and the detection of NO level is pivotal to assess the potential anti-inflammatory effect of a test compound.

We investigated whether PBV could be applied in skin care products for the protection from the degradation of skin collagen and cell death. Our skin is frequently exposed to hazardous environments such as ultraviolet $\mathrm{A}$ and ultraviolet B (UVA and UVB), that may cause inflammatory skin damages, oxidative stress, cellular tissue injuries and cell death, and skin aging $(13,14)$. Chronic exposure to UVB radiation can result in the damage and cell death of keratinocytes and fibroblasts, which represents the main cell population in the epidermis and dermis (15). UVB also promotes variable epidermal thickness, degradation of collagen and elastin fiber by activating elastase and matrix metalloproteinases (MMPs). These findings have been used in the developmental strategy of anti-wrinkle skin care products, such as inhibitors of collagen-degrading enzymes or stimulators of skin cell proliferation in the skin aging. $\mathrm{PBV}$ was prepared by removing $\mathrm{PLA}_{2}$ from regular $\mathrm{BV}$ by ultrafiltration, which produced a biological profile different from BV, with an emphasis on anti-inflammatory and antiwrinkle effects.

\section{MATERIALS AND METHODS}

Reagents. N-Scuccinyl-(L-Ala) 3-p-nitroanilide, porcine pancreatic elastase and penicillin, streptomycin sulfate, dimethyl sulphoxide (DMSO), and Dulbecco's Modified Eagle's Medium (DMEM), 3-(4,5-dimethyl-2-yl)-2,5-diphenyltetrazolium bromide (MTT) and were purchased from Sigma Chemical Co. (St. Louis, MO, USA). All other reagents used were of the purest grade available.

Segregation of $P L A_{2}$ from bee venom. $B V$ and $P B V$ prepared from honey bee (Apis mellifera) are supplied from Chungjin Biotech (Anshan-si, Korea). Briefly, BV was collected using bee venom collector (Chungjin Biotech, Ashansi, Korea) in a sterile manner under strict laboratory conditions. BV collector was placed on the hive, and bees were given electronic shock to cause them to sting onto a glass plate of BV collector from which dried BV was later scraped off. Collected BV was dissolved in distilled water, and then it was filtered using $3.0 \mu \mathrm{m}$ filtration membrane to remove big debris like dust and pollen. Subsequently, 0.45 and $0.2 \mu \mathrm{m}$ membrane filtration were used to eliminate if any tiny debris. The filtered bee venom (BV) was lyophilized and stored at $-20^{\circ} \mathrm{C}$ for later use. $\mathrm{PLA}_{2}$-free bee venom
(PBV) was prepared according to the following procedures. The filtration was conducted using a stirred ultrafiltration (Millipore series 8400, Merck kGaA, Darmstadt, Germany) cell with a $10 \mathrm{kDa}$ molecular weight cut-off membrane (Ultracel PL regenerated cellulose, $76 \mathrm{~mm}$, Millipore Corporation, Bedford, MA, USA). PLA - -free bee venom (PBV) obtained was lyophilized and stored at $-20^{\circ} \mathrm{C}$ for later use.

Measurement of PLA $\boldsymbol{A}_{\mathbf{2}}$ activity. To confirm if $\mathrm{PLA}_{2}$ is sufficiently excluded in PBV by ultrafiltration, $\mathrm{PLA}_{2}$ activity assay was performed for PBV and $\mathrm{BV}$ and compared with each other. Briefly, $\mathrm{PLA}_{2}$ activity was assessed using secretory $\mathrm{PLA}_{2}$ colorimetric assay kit (Cayman Chemical, Ann Arbor, MI, USA) (1). Briefly, the assay uses diheptanoyl phosphatidylcholine as a substrate. Free thiols generated upon the hydrolysis of thioester bond of the substrate at the sn-2 position by $\mathrm{PLA}_{2}$ were detected using DTNB (5,5'-dithio-bis-(2-nitrobenzoic acid)). Color changes were detected using a spectrophotometric microplate reader (BioTek Instruments, Inc., Winooski, VT, USA) at $414 \mathrm{~nm}$ for every minute.

Cell culture. For anti-inflammatory test, RAW264.7 macrophage cells were cultured in DMEM supplemented with $10 \%$ fetal bovine serum (FBS) (Gibco, Rockville, MD, USA), $100 \mathrm{U} / \mathrm{mL}$ penicillin $\mathrm{A}$ and $100 \mathrm{U} / \mathrm{mL}$ streptomycin. For anti-wrinkle test, either human dermal fibroblast (HDF) cell or human keratinocyte $\mathrm{HaCaT}$ cell was grown at $37^{\circ} \mathrm{C}$ in a humidified atmosphere with $95 \%$ air and $5 \% \mathrm{CO}_{2}$. $\mathrm{HDF}$ cell was cultured in $\mathrm{FGM}^{\mathrm{TM}}-2$ BulletKit ${ }^{\mathrm{TM}}$ (Lonza Group Ltd., Basel, Switzerland) and $\mathrm{HaCaT}$ cell was cultured in DMEM. RAW264.7 and HDF cells were purchased from ATCC (American Type Culture Collection, Manassas, VA, USA) and MTCC (Modern cell \& Tissue Technologies, Inc., Seoul, Korea), respectively. HaCaT cell was kindly supplied by Dr. T-J Yoon (Gyeongsang National University, Jinju, Korea).

Elastase inhibition assay. The elastase inhibition was measured by the detection of p-nitroaniline which is released during the hydrolysis of substrate N-Succinyl-(L-Ala)3-pnitroanilide (16). Porcine pancreatic elastase $(2.5 \mathrm{U} / \mathrm{mL})$ was dissolved in $0.25 \mathrm{~mL}$ of $50 \mathrm{mM}$ Tris- $\mathrm{HCl}$ buffer $(\mathrm{pH}$ 8.6) and mixed with $0.5 \mathrm{~mL}$ of a testing sample. As an enzyme substrate, $0.5 \mathrm{~mL}$ of N-Succinyl-(L-Ala)3-p-nitroanilide $(0.5 \mathrm{mg} / \mathrm{mL})$ dissolved in $50 \mathrm{mM}$ Tris-HCl buffer $(\mathrm{pH} 8.6)$ was added to the enzyme mixture. The reaction mixture was incubated for $20 \mathrm{~min}$ at $25^{\circ} \mathrm{C}$, and the reaction product was detected at $405 \mathrm{~nm}$ using ELISA reader (BioTek Instruments, Inc., Winooski, VT, USA). The percentage of inhibition was calculated as: inhibition $(\%)=(1-\mathrm{B} / \mathrm{A}) \times 100$; where $\mathrm{A}$ is the enzyme activity with vehicle and $\mathrm{B}$ is the activity in the presence of testing sample. 
Measurement of NO production. After pre-incubation of RAW264.7 cells $\left(1.5 \times 10^{5}\right.$ cells $\left./ \mathrm{mL}\right)$ with LPS $(1 \mu \mathrm{g} /$ $\mathrm{mL}$ ) for $24 \mathrm{hr}$, the quantity of nitrite accumulated in the culture medium was measured as an indicator of $\mathrm{NO}$ production (17). Briefly, $100 \mu \mathrm{L}$ of cell culture medium was mixed with $100 \mu \mathrm{L}$ of Griess reagent ( $1 \%$ sulfanilamide, $0.1 \%$ naphthylethylenediamine dihydrochloride and 5\% phosphoric acid), the mixture was incubated at room temperature for $10 \mathrm{~min}$, and the absorbance at $550 \mathrm{~nm}$ was measured in a microplate reader (BioTek Instruments, Inc., Winooski, VT, USA). The quantification of nitrite produced was determined from a sodium nitrite standard curve. All the experiments were performed in triplicate.

Gelatin zymography. MMP-2 and MMP-9 activities were determined using gelatin zymography (18). Briefly, $\mathrm{HaCaT}$ cells were seeded $\left(1 \times 10^{5}\right.$ cells/well $)$ and allowed to grow to confluence for $24 \mathrm{hr}$ and maintained in DMEM with $10 \%$ FBS. The cells were washed with PBS and incubated with various concentrations of either BV or PBV ( 0 , 50,100 , and $200 \mu \mathrm{g} / \mathrm{mL}$ ) in serum-free DMEM for $24 \mathrm{hr}$. Then, the supernatant was collected and mixed with nonreducing sample buffer, and electrophoresed in $10 \%$ polyacrylamide gel containing $0.1 \%(\mathrm{w} / \mathrm{v})$ gelatin as a substrate. After the electrophoresis, gel was washed for $30 \mathrm{~min}$ with $2.5 \%$ Triton $\mathrm{X}-100$ twice, then incubated in zymography reaction buffer $(200 \mathrm{mM} \mathrm{NaCl}, 10 \mathrm{mM} \mathrm{CaCl}, 50 \mathrm{mM}$ Tris-HCl, $\mathrm{pH}$ 7.4) for additional $18 \mathrm{hr}$ at $37^{\circ} \mathrm{C}$ for the enzymatic reaction of MMPs. The gel was then stained with Coomassie blue R-250 (0.125\% Coomassie blue R-250, $50 \%$ methanol, and $10 \%$ acetic acid) followed by destaining (methanol/ acetic acid/ water, 40/10/50, v/v/v).

Proliferative ability of HDF cells and determination of cell viability. For HDF cell proliferation assay, HDF cells were seeded to $1 \times 10^{4}$ cells $/ \mathrm{mL}$ in 24 well culture plates in growth medium. After allowing cells to attach, the medium was removed and the cells washed twice in PBS. The cells were then treated with various concentrations of $\mathrm{BV}$ or PBV and incubated for $72 \mathrm{hr}$ in serum free medium. The cell proliferations were determined using MTT assay. Briefly, MTT dye $(5 \mathrm{mg} / \mathrm{mL})$ was added to the cell culture media and they were incubated for additional $3 \mathrm{hr}$. After the medium was removed, DMSO was added to the cells for the solubilization of generated formazan salts. The amount of formazan salt was determined by measuring the optical density (OD) at $540 \mathrm{~nm}$ using GENios ${ }^{\circledR}$ microplate spectrophotometer (PowerWave ${ }^{\mathrm{TM}} \mathrm{XS}$, BioTek Instruments, Inc., Winooski, VT, USA). Relative cell viability of treatment was calculated as a percentage of vehicle-treated control ([OD of treated cells/OD of control] $\times 100$ ). To compare the protective effects of BV and PBV against UVB-induced damage, we investigated $\mathrm{HaCaT}$ cells viability exposed with various levels of UVB or BV preparations for $24 \mathrm{hr}$.
Subsequently, $\mathrm{HaCaT}$ cells were pretreated with $\mathrm{BV}$ or PBV for $2 \mathrm{hr}$, following irradiated with UVB at $40 \mathrm{~mJ} / \mathrm{cm}^{2}$ as described above and cultured in fresh serum-free DMEM.

Statistical analysis. The results are expressed as a mean \pm standard deviation (S.D.). A paired Student's $t$-test was used to assess the significance of differences between two mean values. $p<0.05$ was considered to be statistically significant.

\section{RESULTS}

Preparation of PBV. BV was modified to reduce the incidence of its adverse reactions and improve the safety of its uses in various sectors. The removal of the allergenic component $\mathrm{PLA}_{2}$ from $\mathrm{BV}$ was carried out by the ultrafiltration method using $10 \mathrm{kDa}$ molecular weight cut-off filters. The enzymatic activities of the BV samples were subsequently determined by the $\mathrm{PLA}_{2}$ colorimetric assay to confirm that $\mathrm{PLA}_{2}$ was eliminated. As shown in Fig. 1A, the original $\mathrm{BV}$ demonstrated strong $\mathrm{PLA}_{2}$ activity, whereas PBV retained only a negligible level of PLA $A_{2}$ enzymatic activity. These results suggested that the $\mathrm{PLA}_{2}$ component of $\mathrm{BV}$ was effectively removed by the ultrafiltration method.

Anti-inflammatory effects of PBV. The anti-inflammatory effects of BV have been the subject of many pharmacological studies in animal and human subjects. We examined the comparative inhibitory effect of PBV vs. BV on LPSinduced NO generation from RAW264.7 cells, to determine whether PBV retained the anti-inflammatory effects. Firstly, the concentration ranges for no cellular toxic effects
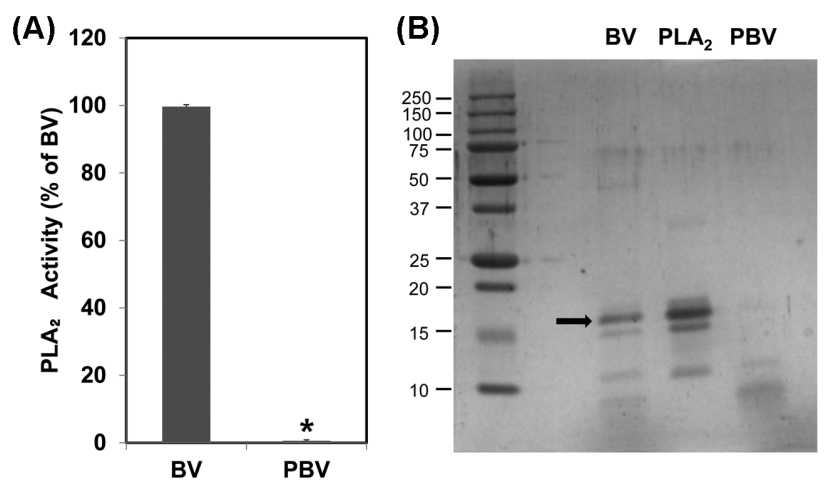

Fig. 1. Confirmation of PBV using PLA $\mathrm{A}_{2}$ assay and SDS-PAGE. In order to detect any residual allergenic component in PBV, PLA assay was performed $(A)$. Then, the protein components of the samples were resolved and compared with each other by SDSPAGE (B). The data shown are the means $\pm S D$ of three experiments performed independently. Significant difference from BV group, ${ }^{*} p<0.05$. 

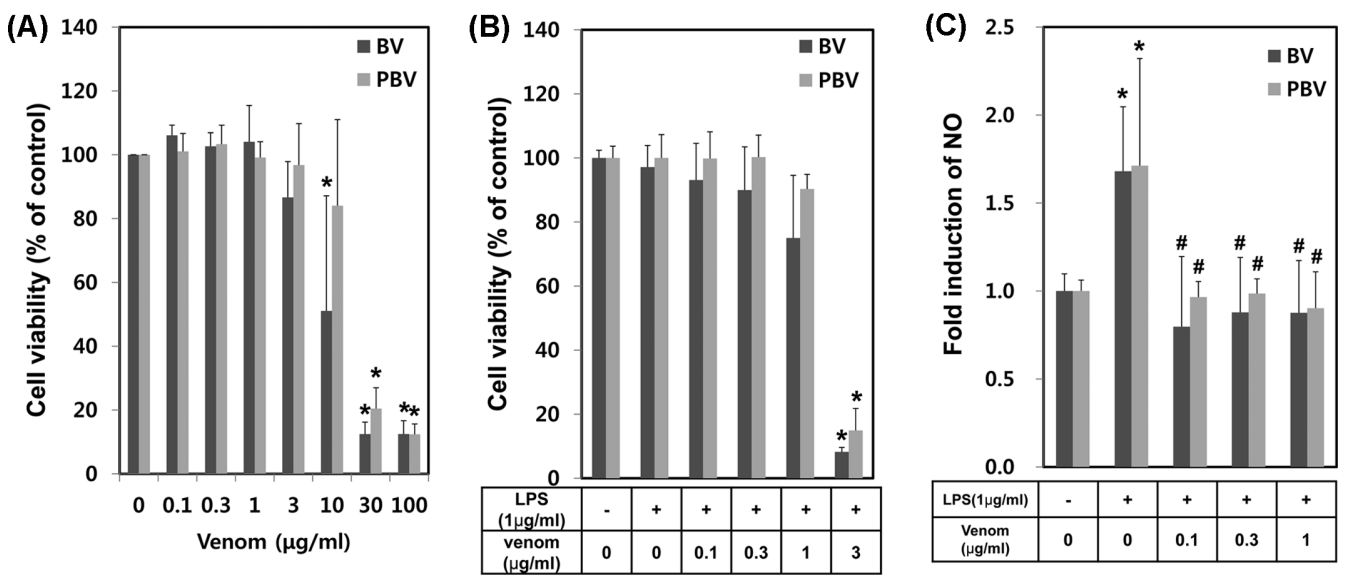

Fig. 2. Comparison of anti-inflammatory effects of BV and PBV. (A) Various concentrations of BV and PBV were applied to macrophage RAW264.7 cells. Briefly, RAW264.7 cells were plated on 24-well and treated with BV and PBV. At 24 hr time period after the treatment, cytotoxicity was measured using MTT assay. (B) RAW264.7 cells were pretreated with LPS for $1 \mathrm{hr}$ and then treated with various concentrations of BV or PBV for additional $24 \mathrm{hr}$, followed by cell viability assessment. (C) The anti-inflammatory effects of BV and PBV on RAW264.7 were evaluated. At $24 \mathrm{hr}$ time period after the treatment of LPS ( $1 \mu \mathrm{g} / \mathrm{mL})$, NO induction level was detected by Griess solution. The data shown are the means \pm SD of three independent experiments. Significant difference from control group, ${ }^{*} p<0.05$. Significant difference from LPS control group, ${ }^{*} p<0.05$.
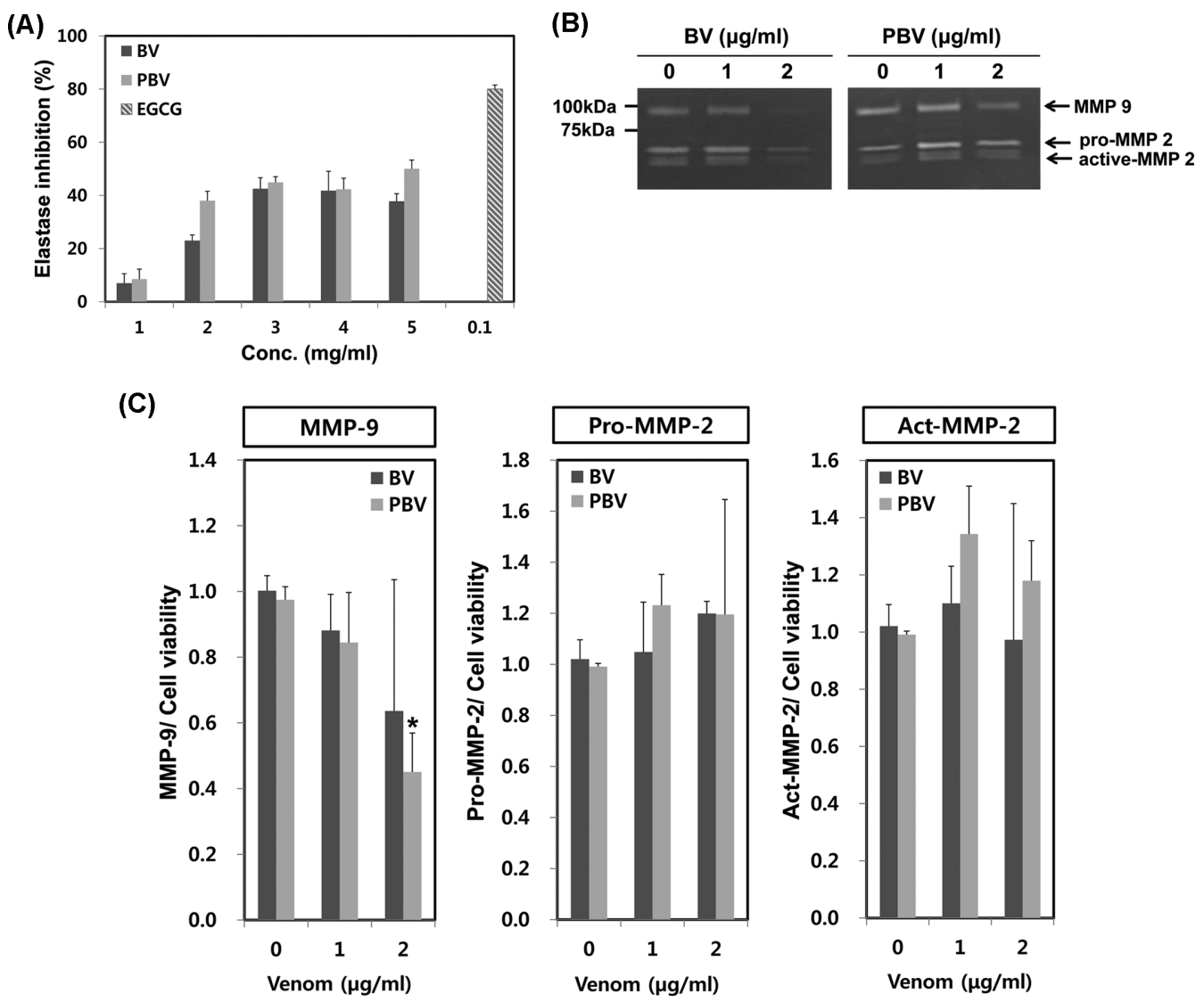

Fig. 3. Comparison of anti-wrinkle effects of BV and PBV. (A) Elastse inhibition assay was performed by Cannell's method with a slight modification. Various concentrations of BV or PBV were mixed with N-succinyl-(L-Ala)3-p-nitroanilide $(0.5 \mathrm{mg} / \mathrm{mL})$. EGCG $(0.1 \mathrm{mg} / \mathrm{mL})$ was used for positive control. (B) HaCaT cells were plated on 6-well plates for $24 \mathrm{hr}$, then the cells were treated with various concentrations $(0,1,2 \mu \mathrm{g} / \mathrm{mL})$ of BV and PBV for additional $24 \mathrm{hr}$. MMP-2 and MMP-9 expressions were calculated comparing cell viability. The data shown are the means \pm SD of three experiments. Significant difference from control group, ${ }^{*} p<0.05$. 
were determined by BV preparation dose-response studies. A dramatic increase in cytotoxicity at concentrations $\geq 10 \mu \mathrm{g} / \mathrm{mL}$ was observed (Fig. 2A). Upon co-treatment with LPS $(1 \mu \mathrm{g} / \mathrm{mL})$, cytotoxicities were highly enhanced and showed no more than $15 \%$ of cell viability even at $3 \mu \mathrm{g} / \mathrm{mL}$ of BV and PBV (Fig. 2B). The inhibitory activities on LPS-induced NO generation were determined in RAW264.7 cells, in the absence or presence of $0.1,0.3$ or $1 \mu \mathrm{g} / \mathrm{mL}$ of each BV preparation. LPS alone induced an augmentation of NO generation. The co-treatment of BV showed a significant suppression of LPS-induced NO generation for all BV preparations (Fig. 2C). The results indicated that PBV retains anti-inflammatory activity comparable to BV.

\section{Inhibitory effects of BV preparations on elastase} activity. Elastin, a major component of the skin dermis, can be easily destroyed by elastase upon exposure to some causative factors (UV light or reactive oxygen species). As a result, extracellular matrix (ECM) is degraded and the skin undergoes aging-like changes such as wrinkling, fragility and loss of elasticity. Elastase inhibition assay is thus very important for the evaluation of skin wrinkling. BV and PBV concentration-dependently had significant elastase inhibitory effects (Fig. 3A). This result suggested that PBV preparations may have beneficial effects on skin protection when used as a cosmetic ingredient.

Suppression of MMP-9 activity by BV preparations. We next evaluated the inhibitory effect of BV and PBV on the degradation of ECM. BV or PBV-mediated changes in MMP-2 and MMP-9 activities were determined by zymog-
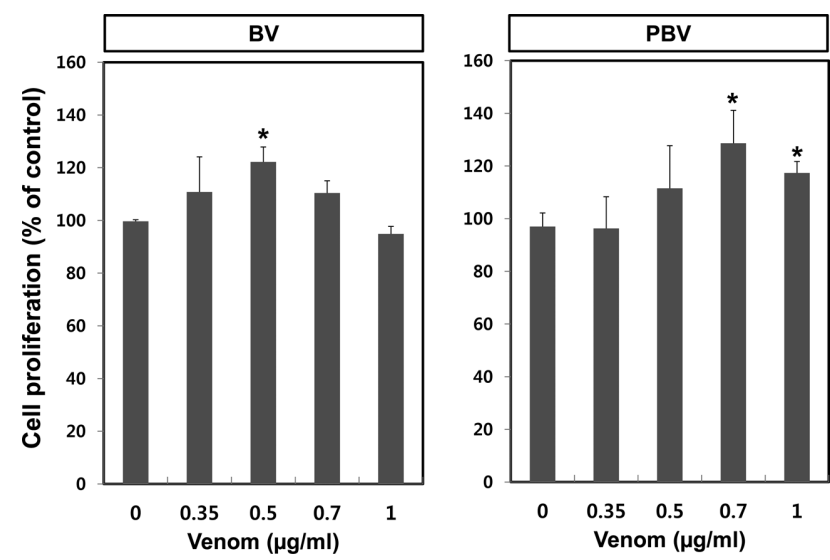

Fig. 4. Comparison of proliferative effects of BV and PBV on HDF cells. For starting the experiment, the culture medium of HDF cell was changed to serum free medium and then the cells were treated with either BV or PBV for $72 \mathrm{hr}$. Cell proliferation was measured using MTT assay. The data shown are the means $\pm S D$ of three experiments. Significant difference from control group, ${ }^{*} p<0.05$. raphy in human skin keratinocyte (HaCaT) cells. Both BV and PBV concentration-dependently inhibited MMP-9 activity (Fig. 3B and 3C). PBV $(2 \mu \mathrm{g} / \mathrm{mL})$ most potently suppressed MMP-9 activity to $<50 \%$ of the control level. However, activities of pro-/active-MMP-2 were not significantly modulated by treatments with BV and PBV (Fig. 3B and $3 \mathrm{C})$.

Cell proliferative effect of BV preparations on human dermal fibroblast (HDF). HDF cell proliferation is an important indicator for the anti-wrinkle test because HDF cells produce collagen and elastin in the dermis. Proliferation assay was conducted using an HDF cell line to examine whether BV and PBV have anti-wrinkle effects. Among
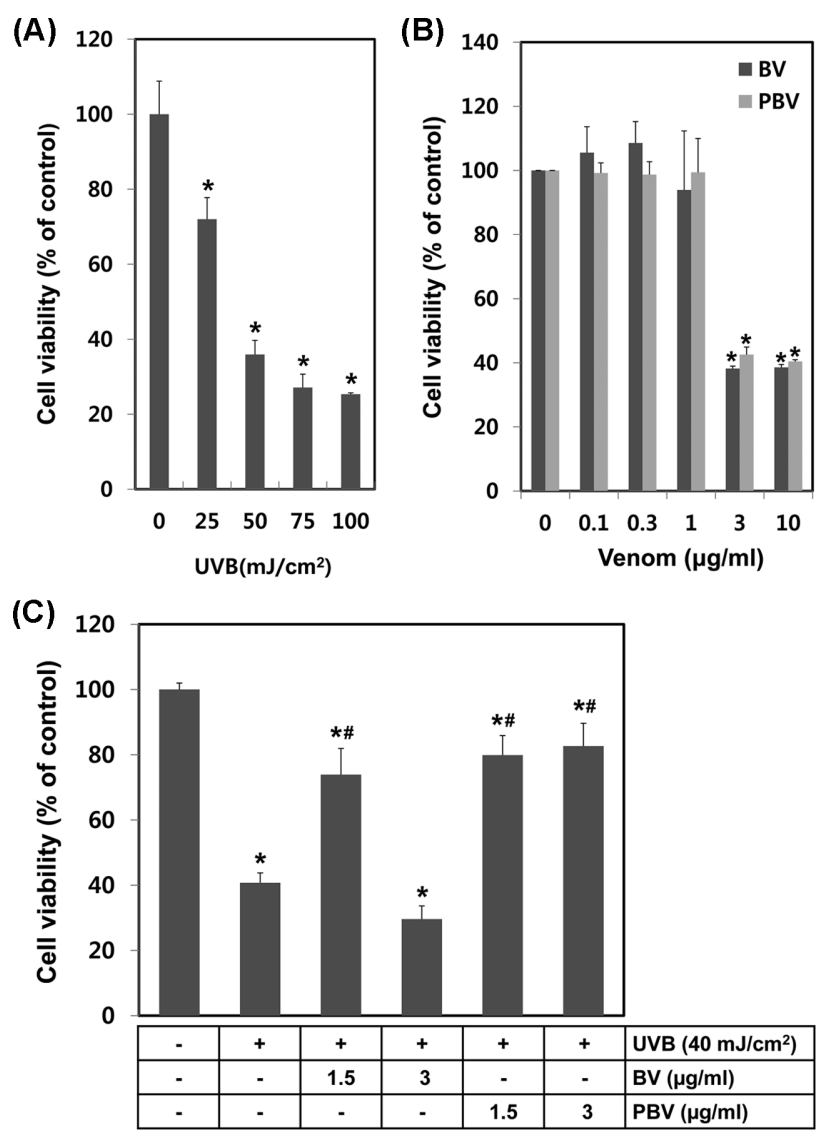

Fig. 5. Comparison of protective effects of $B V$ and PBV in UVB damaged $\mathrm{HaCaT}$ cells. (A) HaCaT cells were irradiated with various energies UVB and the after $24 \mathrm{hr}$ cell viability was measured using MTT assay. (B) Cell cytotoxicity of various concentration $(0 \sim 10 \mu \mathrm{g} / \mathrm{mL})$ of BV or PBV. In order to measurement of cytotoxicity we used MTT assay. (C) Protective effects test of BV or PBV in UVB damaged $\mathrm{HaCaT}$ cells. HaCaT cells were plated on 24 well and then changed serum free medium. HaCaT cells were irradiated by UVB and then incubated with BV or PBV for $24 \mathrm{hr}$. The data shown are the means \pm SD of three experiments. Significant difference from control group, ${ }^{*} p<0.05$. Significant difference from UVB irradiated group, ${ }^{\sharp} p<0.05$. 
the BV preparations tested, PBV at $0.7 \mu \mathrm{g} / \mathrm{mL}$ showed the highest rate of HDF cell proliferation (Fig. 4). This result implied that while all of the BV are effective, PBV appears to be the most promising anti-wrinkle agent without $\mathrm{PLA}_{2}-$ associated side effects.

Protective effects of BV preparations against UVBinduced damage. The protective effect of $\mathrm{BV}$ and $\mathrm{PBV}$ against UVB-induced skin damage was evaluated in $\mathrm{HaCaT}$ cells. Cell viability was determined by the MTT assay postUVB irradiation with BV preparations or vehicle alone pretreatments. HaCaT cells were irradiated with various energy levels of UVB in the range of 25 to $100 \mathrm{~mJ} / \mathrm{cm}^{2}$. UVB irradiation, in an energy level-dependent manner, significantly decreased cell viability (Fig. $5 \mathrm{~A}$ ). The calculated $\mathrm{LC}_{50}$ of UVB irradiation was $41.407 \mathrm{~mJ} / \mathrm{cm}^{2}$. HaCaT cells were treated with various concentrations of $\mathrm{BV}$ or PBV to determine the cytotoxic concentration of BV or PBV. Cell viability remained unaltered up to $1 \mu \mathrm{g} / \mathrm{mL}$ of the treatment; whereas there was significant loss of cell viability at $\geq 3 \mu \mathrm{g} /$ $\mathrm{mL}$ for both $\mathrm{BV}$ and PBV (Fig. 5B). HaCaT cells were pretreated with $\mathrm{BV}$ or $\mathrm{PBV}$ for $2 \mathrm{hr}$ and then exposed to $40 \mathrm{~mJ} / \mathrm{cm}^{2} \mathrm{UVB}$, to examine protective effects against UVB radiation. All treatments of $\mathrm{BV}$ and $\mathrm{PBV}$, except $3 \mu \mathrm{g} /$ $\mathrm{mL}$ of $\mathrm{BV}$, demonstrated protective effects against UVB exposure at $40 \mathrm{~mJ} / \mathrm{cm}^{2}$. Cell survival data indicated that PBV optimally protected against UVB-mediated cell damage. BV was protective against UVB-induced cytotoxicity at $1.5 \mu \mathrm{g} / \mathrm{mL}$, but caused more cytotoxicity at $3 \mu \mathrm{g} / \mathrm{mL}$, unlike PBV. The experimental data showed that PBV had superior protective effects against UVB damage, as compared to BV.

\section{DISCUSSION}

For centuries BV has been used as a complementary medicine to treat a variety of illnesses in Oriental medicine. In America, Russia and Eastern Europe, it has also been employed in BV therapy and bee acupuncture therapy for arthritis and multiple sclerosis. Generally, honey bee (Apis mellifera) venom contains various kinds of pharmacologically and/or toxicologically active elements, including melittin, apamin, adolapin and $\mathrm{PLA}_{2}$. Melittin is the main component of the honey bee venom and constitutes 40 to $60 \%$ of dry venom. It has well known anti-bacterial and anti-viral activities (19). Apamin was reported to protect against dopaminergic neurons, and cause a small increase in excitability of dopaminergic neurons, leading to a moderate and persistent elevation in cytosolic calcium (20). Although the use of BV has steadily increased in traditional Korean medicine clinics, as well as an active ingredient of cosmeceuticals, the concern over adverse reactions (local pain, edema and uredo and infrequent severe anaphylaxis) has been an obstacle to its more widespread use. PLA 2 is a major BV allergen that induces adverse effects such as pain and inflammation; it directly stimulates degranulation of mast cells and indirectly induces leukotrienes, thus promoting inflammation (8). For the safe use of BV in pharmaceuticals or cosmeceuticals, it is required that $\mathrm{PLA}_{2}$ is removed from $\mathrm{BV}$ to reduce the allergenic adverse reaction. The aim of this study was to prepare $\mathrm{PLA}_{2}$-free $\mathrm{BV}$ and evaluate the comparative biological functions with regular $\mathrm{BV}$ for its potential use in the treatment of various diseases, as well as in cosmetic products.

We applied a rapid and efficient ultrafiltration method for removal of $\mathrm{PLA}_{2}$ from $\mathrm{BV}$. Ultrafiltration was a simple and convenient method of $\mathrm{PLA}_{2}$ elimination from $\mathrm{BV}$. We obtained more stable and larger amounts of active components than previous methods such as gel filtration and chromatography (data not shown). We performed the $\mathrm{PLA}_{2}$ activity assay to verify if most $\mathrm{PLA}_{2}$ was removed from the $\mathrm{BV}$ preparations. The results showed that PBV included only minimal amounts of $\mathrm{PLA}_{2}$ compared to regular $\mathrm{BV}$ (Fig. 1A). Ultrafiltration can thus be successfully employed as a method of $\mathrm{PLA}_{2}$ elimination from BV.

The efficacy of PBV as an active ingredient of pharmaceuticals or cosmeceuticals was tested using various biological assays (anti-inflammation, elastase and MMPs inhibition and cell proliferation). Firstly, we examined if PBV retained the typical BV anti-inflammatory effect by measuring NO levels. Previous studies demonstrated that LPS induces iNOS and COX -2 mRNA and NF- $\kappa \mathrm{B}$ activation, while BV inhibits iNOS and COX-2 expression via NF- $\mathrm{B}$ inactivation in RAW264.7 cells (3). Another study showed that BV suppressed NO production through inhibition of iNOS and $\mathrm{NF}-\kappa \mathrm{B}$ expression in glioma cells (21). These results suggested that the $\mathrm{BV}$-induced NO suppression is mediated by the inhibition of iNOS and NF- $\mathrm{BB}$. Our present study showed that BV and PBV decreased LPS-induced NO levels, but not the basal production of NO (Fig. 2C). Although we did not show that the BV and PBV-mediated NO suppression was associated with the modulation of its upstream regulators (iNOS and NF- $\mathrm{B}$ ), previous reports clearly showed that both $\mathrm{BV}$ and $\mathrm{PBV}$ exhibit anti-inflammatory effects. However, PBV is more suitable as an anti-inflammatory agent, since BV is more toxic in RAW264.7 cells at the same concentration $(1 \mu \mathrm{g} / \mathrm{mL})$. Secondly, we investigated if PBV had an anti-wrinkle effect by measuring its inhibitory effects on elastase and MMP enzymes. Elastin and ECM are easily destroyed by elastase and MMPs in aged and UVB damaged skin. Elastase inhibition test is performed as the initial assessment of anti-wrinkle effects of $\mathrm{BV}$ and PBV. Elastase activity was attenuated by PBV more than BV. PBV had more potential for elastase inhibition, as compared to BV at all concentrations (Fig. 3A). The results of the MMPs inhibition test showed that PBV had a stronger MMP-9 inhibitory activity than BV at $2 \mu \mathrm{g} / \mathrm{mL}$. MMP9 is a UVB-inducible enzyme that plays a pivotal role in 
wrinkle formation, and leads to abnormal matrix degradation and accumulation of non-functional matrix components (22). Furthermore, human dermal fibroblast is one of the most important targets in wrinkle formation, since it can stimulate the production of collagen and elastin (23). Therefore, HDF cell proliferation is an indicative assay of antiwrinkle reagents. Results of the proliferation test indicated that PBV stimulated higher HDF cell growth, though BV had potential at lower concentrations (Fig. 4). Finally, we investigated the effect of PBV on UVB-irradiated skin damage by the MTT assay. As a primary component in the epidermis, keratinocytes are the primary target of external environmental exposure. All concentrations of $\mathrm{BV}$ and PBV, except BV $3 \mu \mathrm{g} / \mathrm{mL}$, were protective against UVB induced HaCaT cell death. However, PBV is superior to $\mathrm{BV}$ in recovery rate and non-induction of cytotoxicity. These data demonstrated that PBV can be readily accessible and safe for use as a therapeutic and/or cosmetic ingredient.

In conclusion, the ultrafiltration method can conveniently eliminate the allergenic $\mathrm{PLA}_{2}$ protein from $\mathrm{BV}$, and enable mass production of PBV with a low risk of adverse reactions. Based on the prominent protective effect on UVBinduced damage in HaCaT cells, PBV can be safely used for potential anti-inflammatory and anti-wrinkle activities.

\section{ACKNOWLEDGEMENTS}

This Research was supported by 'Agricutural Biotechnology Development Program', Ministry of Agriculture, Food and Rural Affairs.

\section{REFERENCES}

1. Son, D.J., Lee, J.W., Lee, Y.H., Song, H.S., Lee, C.K. and Hong, J.T. (2007) Therapeutic application of anti-arthritis, pain-releasing, and anti-cancer effects of bee venom and its constituent compounds. Pharmacol. Ther., 115, 246-270.

2. Han, S.M., Lee, K.G. and Pak, S.C. (2013) Effects of cosmetics containing purified honeybee (Apis mellifera L.) venom on acne vulgaris. J. Integr. Med., 11, 320-326.

3. Park, H.J., Lee, S.H., Son, D.J., Oh, K.W., Kim, K.H., Song, H.S., Kim, G.J., Oh, G.T., Yoon, D.Y. and Hong, J.T. (2004) Antiarthritic effect of bee venom: Inhibition of inflammation mediator generation by suppression of NF- $\mathrm{KB}$ through interaction with the p50 subunit. Arthritis Rheum., 50, 3504-3515.

4. Kang, S.S., Pak, S.C. and Choi, S.H. (2002) The effect of whole bee venom on arthritis. Am. J. Chin. Med., 30, 73-80.

5. Kwon, Y.B., Lee, H.J., Han, H.J., Mar, W.C., Kang, S.K., Yoon, O.B., Beitz, A.J. and Lee, J.H. (2002) The water-soluble fraction of bee venom produces antinociceptive and antiinflammatory effects on rheumatoid arthritis in rats. Life Sci., 71, 191-204.

6. Liu, X., Chen, D., Xie, L. and Zhang, R. (2002) Effect of honey bee venom on proliferation of K1735M2 mouse melanoma cells in-vitro and growth of murine B16 melanomas in- vivo. J. Pharm. Pharmacol., 54, 1083-1089.

7. Oršolić, N., Šver, L., Verstovšek, S., Terzić, S. and Bašić, I. (2003) Inhibition of mammary carcinoma cell proliferation in vitro and tumor growth in vivo by bee venom. Toxicon, 41, 861-870.

8. Mustafa, F.B., Ng, F.S., Nguyen, T.H. and Lim, L.H. (2008) Honeybee venom secretory phospholipase A2 induces leukotriene production but not histamine release from human basophils. Clin. Exp. Immunol., 151, 94-100.

9. Chang, Y.H. and Bliven, M.L. (1979) Anti-arthritic effect of bee venom. Agents Actions, 9, 205-211.

10. Lee, J.D., Kim, S.Y., Kim, T.W., Lee, S.H., Yang, H.I., Lee, D.I. and Lee, Y.H. (2004) Anti-inflammatory effect of bee venom on type II collagen-induced arthritis. Am. J. Chin. Med., 32, 361-367.

11. Zurier, R.B., Mitnick, H., Bloomgarden, D. and Weissmann, G. (1973) Effect of bee venom on experimental arthritis. Ann. Rheum. Dis., 32, 466-470.

12. Billingham, M.E., Morley, J., Hanson, J.M., Shipolini, R.A. and Vernon, C.A. (1973) Letter: An anti-inflammatory peptide from bee venom. Nature, 245, 163-164.

13. Kim, J.K., Kim, Y., Na, K.M., Surh, Y.J. and Kim, T.Y. (2007) [6]-Gingerol prevents UVB-induced ROS production and COX-2 expression in vitro and in vivo. Free Radical Res., 41, 603-614.

14. Nichols, J.A. and Katiyar, S.K. (2010) Skin photoprotection by natural polyphenols: anti-inflammatory, antioxidant and DNA repair mechanisms. Arch. Dermatol. Res., 302, 71-83.

15. Fisher, G.J., Kang, S., Varani, J., Bata-Csorgo, Z., Wan, Y., Datta, S. and Voorhees, J.J. (2002) Mechanisms of photoaging and chronological skin aging. Arch. Dermatol., 138, 1462-1470.

16. Cannell, R.J., Kellam, S.J., Owsianka, A.M. and Walker, J.M. (1988) Results of a large scale screen of microalgae for the production of protease inhibitors. Planta Med., 54, 10-14.

17. Kim, H.G., Shrestha, B., Lim, S.Y., Yoon, D.H., Chang, W.C., Shin, D.J., Han, S.K., Park, S.M., Park, J.H., Park, H.I., Sung, J.M., Jang, Y., Chung, N., Hwang, K.C. and Kim, T.W. (2006) Cordycepin inhibits lipopolysaccharide-induced inflammation by the suppression of NF-kappaB through Akt and p38 inhibition in RAW264.7 macrophage cells. Eur. J. Pharmacol., 545, 192-199.

18. Garbisa, S., Sartor, L., Biggin, S., Salvato, B., Benelli, R. and Albini, A. (2001) Tumor gelatinases and invasion inhibited by the green tea flavanol epigallocatechin-3-gallate. Cancer, 91, $822-832$.

19. Bucki, R., Pastore, J.J., Randhawa, P., Vegners, R., Weiner, D.J. and Janmey, P.A. (2004) Antibacterial activities of rhodamine B-conjugated gelsolin-derived peptides compared to those of the antimicrobial peptides cathelicidin LL37, magainin II, and melittin. Antimicrob. Agents Chemother., 48, 1526-1533.

20. Salthun-Lassalle, B., Hirsch, E.C., Wolfart, J., Ruberg, M. and Michel, P.P. (2004) Rescue of mesencephalic dopaminergic neurons in culture by low-level stimulation of voltage-gated sodium channels. J. Neurosci., 24, 5922-5930.

21. Lee, K.G., Cho, H.J., Bae, Y.S., Park, K.K., Choe, J.Y., Chung, I.K., Kim, M., Yeo, J.H., Park, K.H., Lee, Y.S., Kim, C.H. and Chang, Y.C. (2009) Bee venom suppresses LPS-mediated NO/ 
iNOS induction through inhibition of PKC-alpha expression. J. Ethnopharmacol., 123, 15-21.

22. Fineschi, S., Cozzi, F., Burger, D., Dayer, J.M., Meroni, P.L. and Chizzolini, C. (2007) Anti-fibroblast antibodies detected by cell-based ELISA in systemic sclerosis enhance the collag- enolytic activity and matrix metalloproteinase-1 production in dermal fibroblasts. Rheumatology (Oxford), 46, 1779-1785.

23. Berman, M.B. (1994) Regulation of corneal fibroblast MMP1 secretion by cytochalasins. Cornea, 13, 51-57. 